\title{
Recommended Medical and Non-Medical Factors to Assess Military Preventable Deaths: Subject Matter Experts Provide Valuable Insights
}

Whitney Y. Harrison

Joint Trauma System

Jana L. Wardian PhD

University of Nebraska Medical Center, jana.wardian@unmc.edu

\section{J.A. Sosnov \\ Clinical Medicine}

R.S. Kotwal

Joint Trauma Sytem

F.K. Butler

Joint Trauma Sytem

See next page for additional authors

Tell us how you used this information in this short survey.

Follow this and additional works at: https://digitalcommons.unmc.edu/com_hosp_articles

\section{Recommended Citation}

Harrison, Whitney Y.; Wardian, Jana L. PhD; Sosnov, J.A.; Kotwal, R.S.; Butler, F.K.; Stockinger, Z.T.;

Shackelford, S.A.; Gurney, J.M.; Spott, M.A.; Finelli, L.N.; Mazuchowski, E.L.; Smith, D.J.; and Janak, J.C., "Recommended Medical and Non-Medical Factors to Assess Military Preventable Deaths: Subject Matter Experts Provide Valuable Insights" (2020). Journal Articles: Hospital Medicine. 27.

https://digitalcommons.unmc.edu/com_hosp_articles/27

This Article is brought to you for free and open access by the Hospital Medicine at DigitalCommons@UNMC. It has been accepted for inclusion in Journal Articles: Hospital Medicine by an authorized administrator of DigitalCommons@UNMC.For more information, please contact digitalcommons@unmc.edu. 
Authors

Whitney Y. Harrison, Jana L. Wardian PhD, J.A. Sosnov, R.S. Kotwal, F.K. Butler, Z.T. Stockinger, S.A. Shackelford, J.M. Gurney, M.A. Spott, L.N. Finelli, E.L. Mazuchowski, D.J. Smith, and J.C. Janak 


\title{
Recommended medical and non-medical factors to assess military preventable deaths: subject matter experts provide valuable insights
}

\author{
Whitney Y Harrison, ${ }^{1} \mathrm{~J}$ L Wardian, ${ }^{2} \mathrm{~J}$ A Sosnov, ${ }^{3}$ R S Kotwal, ${ }_{1}^{1}$ F K Butler, ${ }^{1}$ \\ Z T Stockinger, ${ }^{1}$ S A Shackelford, ${ }^{1}$ J M Gurney, ${ }^{1}$ M A Spott, ${ }^{1}$ L N Finelli, ${ }^{4}$ \\ E L Mazuchowski, ${ }^{1,4}$ D J Smith, ${ }^{5}$ J C Janak ${ }^{1}$
}

- Additional material is published online only. To view please visit the journal online (http://dx.doi.org/10.1136/ jramc-2019-001193)

${ }^{1}$ Joint Trauma System, San Antonio, Texas, USA ${ }^{2}$ Wilford Hall Ambulatory Surgical Center, San Antonio, Texas, USA

${ }^{3}$ Clinical Medicine, 375 MDOS, Scott AFB, Illinois, USA

${ }^{4}$ Armed Forces Medical Examiner System, Dover, Delaware, USA

${ }^{5}$ Health Affairs, Falls Church, Virginia, USA

\section{Correspondence to} Whitney Y Harrison, Joint Trauma System, JBSA Ft. Sam Houston, Texas 78234, USA; whitney.y.harrison2.ctr@mail. mil

Received 14 February 2019 Revised 28 March 2019 Accepted 29 March 2019 Published Online First 29 April 2019

Check for updates

(C) Author(s) (or their employer(s)) 2020. No commercial re-use. See rights and permissions. Published by BMJ.

To cite: Harrison WY,

Wardian JL, Sosnov JA, et al. BMJ Mil Health

2020;166:e47-e52

\section{ABSTRACT}

Introduction Historically, there has been variability in the methods for determining preventable death within the US Department of Defense. Differences in methodologies partially explain variable preventable death rates ranging from $3 \%$ to $51 \%$. The lack of standard review process likely misses opportunities for improvement in combat casualty care. This project identified recommended medical and non-medical factors necessary to (1) establish a comprehensive preventable death review process and (2) identify opportunities for improvement throughout the entire continuum of care.

Methods This qualitative study used a modified rapid assessment process that includes the following steps: (1) identification and recruitment of US government subject matter experts (SMEs); (2) multiple cycles of data collection via key informant interviews and focus groups; (3) consolidation of information collected in these interviews; and (4) iterative analysis of data collected from interviews into common themes. Common themes identified from SME feedback were grouped into the following subject areas: (1) prehospital, (2) in-hospital and (3) forensic pathology.

Results Medical recommendations for military preventable death reviews included the development, training, documentation, collection, analysis and reporting of the implementation of the Tactical Combat Casualty Care Guidelines, Joint Trauma System Clinical Practice Guidelines and National Association of Medical Examiners autopsy standards. Non-medical recommendations included training, improved documentation, data collection and analysis of non-medical factors needed to understand how these factors impact optimal medical care.

Conclusions In the operational environment, medical care must be considered in the context of non-medical factors. For a comprehensive preventable death review process to be sustainable in the military health system, the process must be based on an appropriate conceptual framework implemented consistently across all military services.

\section{BACKGROUND}

Explicit guidelines and standardised processes to conduct military preventable death reviews do not exist for the US Department of Defense (DoD). Preventable death can be defined as a death that occurred from a medically survivable or potentially survivable injury when the non-medical situation

\section{Key messages}

- There is a need for a standardised, Department of Defense-wide military preventable death review process.

- Medical and non-medical recommendations should be evaluated when conducting a military preventable death review.

- These recommendations should be routinely evaluated and revised, as necessary, to determine feasibility, relevance and efficacy.

did not impede optimal medical care. Methods for determining preventable death rates are often diverse and ambiguous, and yield inconsistent results ranging from $3 \%$ to $51 \% .^{1}$ Further, lack of supporting policy for preventable death determinations in the operational environment leads to missed opportunities for improvement in combat casualty care. To address these gaps and meet the goal of zero preventable deaths after injury, ${ }^{2}$ the Joint Trauma System (JTS) and Armed Forces Medical Examiner System (AFMES) were tasked with recommending and establishing a process for conducting preventable death reviews for the DoD.

A multidisciplinary preventable death group, formed by the JTS and AFMES, developed a conceptual framework ${ }^{3}$ to direct their efforts for establishing a valid and reliable military preventable death process. This framework is driving work such as (1) review of the existing literature $^{1}$; (2) establishing a DoD Trauma Morbidity and Mortality Surveillance System; (3) analyses of survivability metrics; and (4) qualitative assessment of prehospital, in-hospital and forensic pathology recommendations for military preventable death reviews. Recommendations established during step 4 , the qualitative assessment, are presented in this manuscript.

\section{METHODS}

Adapted rapid assessment process: a validated, standardised methodology

A qualitative study was implemented using an adapted rapid assessment process, ${ }^{4-6}$ a validated, standardised methodology for conducting qualitative research that includes the following steps: (1) identification of subject matter experts (SMEs)/ 


\begin{tabular}{llll}
\hline Table 1 & SME count by US military service & \\
\hline & & Internal SMEs & $\begin{array}{l}\text { External } \\
\text { SMEs }\end{array}$ \\
\hline Army & Prehospital & 1 & 4 \\
& In-hospital & 1 & 1 \\
& Forensic pathology & 1 & 0 \\
Navy & Prehospital & 1 & 0 \\
& In-hospital & 1 & 1 \\
& Forensic pathology & 0 & 0 \\
Air Force & Prehospital & 0 & 1 \\
& In-hospital & 1 & 1 \\
& Forensic pathology & 1 & 0 \\
\hline
\end{tabular}

SME, subject matter expert.

project participants; (2) multiple cycles of data collection via key informant interviews and focus groups; (3) consolidating information from data collected in these interviews; and (4) iterative analysis of data collected from these interviews into important main themes. Data collection continued until no new ideas or thoughts were presented by SMEs. Common themes identified through these interviews and discussions with SMEs were then compiled to create recommendations for the planning and implementation of new and existing policies, processes and procedures to reduce preventable death.

\section{Internal SME selection and data collection}

For the current project, researchers began the qualitative assessment process by identifying internal US government SMEs who are or have been active-duty healthcare providers. Feasibility sampling was implemented to identify internal SMEs within the JTS and AFMES for three primary subject areas: prehospital, in-hospital and forensic pathology. Multiple rounds of key informant interviews and focus groups were conducted with internal SMEs until no new ideas or thoughts were presented.

\section{External SME selection and data collection}

Once data collection with internal SMEs was completed, internal SMEs recruited experts outside of the JTS to participate. Similar to the internal SMEs, all external SMEs are or have been active-duty healthcare providers. External SME selection was based on prior military position and background, as well as medical specialty and experience in combat casualty care (see Table 1 for SME characteristics). To solicit participation from external SMEs, one internal SME from each of the three subject areas sent an email message requesting participation from the selected external SMEs. Potential external SMEs were provided background information and goals of the project, as well as an explanation of how they were selected as SMEs. Additionally, external SMEs were provided a draft of the discussion findings previously developed by the internal SMEs with instructions to not distribute to others outside of the project. The external SMEs followed the same qualitative process as JTS SMEs until no new ideas or thoughts were presented. All SMEs had valuable experience with patients in their respective specialty areas. Prehospital, in-hospital and forensic pathologist SMEs reported well over 2000, 3000 and 1700 patient encounters, respectively.

Eight discussions with internal and external SMEs were conducted: six key informant interviews and two focus groups with each group including seven participants. The decision to conduct a focus group or key informant interview was based on the availability of each SME. All focus groups and interviews were digitally recorded. Transcription was conducted after all focus groups and interviews were completed. Predetermined questions (online supplementary appendix A) were prepared and distributed to participants prior to the focus group or interview to ensure that discussions addressed a priori questions and participants had time to consider their responses.

\section{Consolidation and iterative analysis of findings into recommendations to reduce preventable death}

Transcripts, field notes and observational information, gathered from focus groups and key informant interviews, were systematically analysed. Consolidation and review of interview findings, steps 3 and 4 of the rapid assessment process, were used to identify common themes and categories within and between each focus group and interview. Common themes identified across all discussions with SMEs were grouped into medical and non-medical recommendations according to each of the three predetermined subject areas: prehospital, in-hospital and forensic pathology. These recommendations are presented in the synthesis below.

\section{FINDINGS}

Researchers requested feedback from 19 internal and external SMEs: eight prehospital SMEs, eight in-hospital SMEs and three forensic pathology SMEs. Of the 12 external SMEs contacted, six provided feedback, resulting in a response rate of $50 \%$ among external SMEs. All seven internal SMEs participated in the project.

Themes identified within and between SME groups were placed into two broad categories: medical and non-medical recommendations. The synthesis below identifies the medical and non-medical recommendations, broken out by specialty area. An overall synthesis of findings from each SME group is presented in Figure 1 and discussed in more detail below.

\section{Summary of recommendations to optimise combat casualty care and reduce preventable death}

Across the continuum of care (ie, prehospital, in-hospital and forensic pathology), there were several themes identified as recommendations to improve the US military preventable death review process to reduce preventable death through actionable opportunities for improvement (Figure 1). All SMEs have identified recommendations to optimise combat casualty care and reduce preventable death (Box 1).

\section{Prehospital recommendations}

Prehospital care was defined as care provided from the point of injury through transport, up to arrival at a medical treatment facility (MTF). Care provided in the prehospital setting is coordinated by non-medical leaders and medical support personnel for organisations whose primary function is not medical care. The following are the prehospital medical and non-medical recommendations for evaluating a death that occurred in the prehospital setting.

\section{Medical recommendations}

\section{Prehospital medical standards: Tactical Combat Casualty Care}

"Deciding standards for prehospital combat trauma care is a complex mix of following the prehospital trauma care literature, listening to combat casualty care presentations, talking to medics, and listening to experiences of other militaries."-SME 1 and 2

Trauma care provided in the prehospital combat setting is governed by the Tactical Combat Casualty Care (TCCC) 


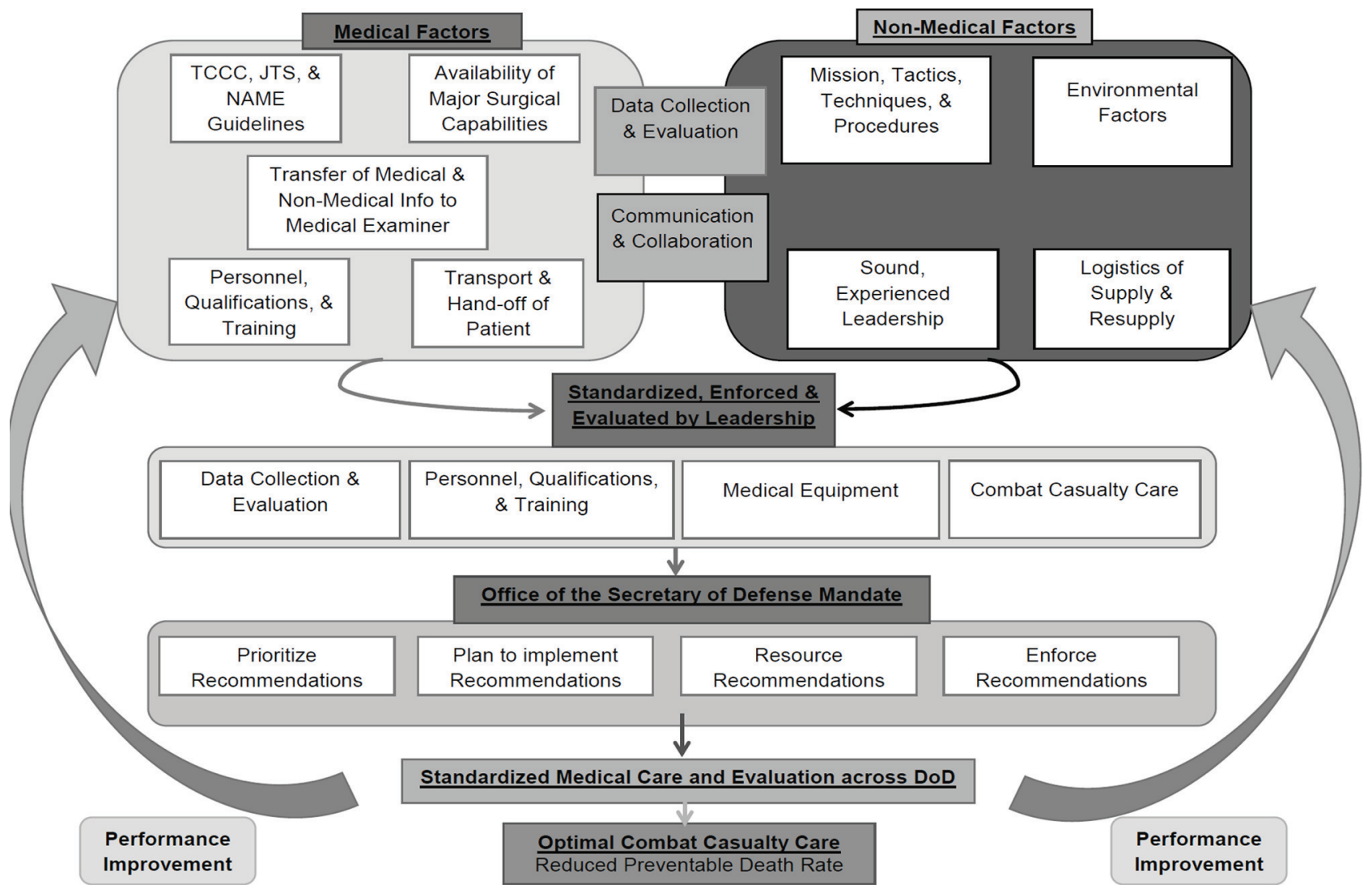

Figure 1 Preventable death conceptual framework. DoD, Department of Defense; JTS, Joint Trauma System; TCCC, Tactical Combat Casualty Care; NAME, National Association of Medical Examiners.

Guidelines. SMEs stated the importance of consistently and routinely reviewing these guidelines to identify areas for process improvement in a combat setting. Deviations from these guidelines in the prehospital setting could contribute to preventable

Box 1 Summary of recommendations to optimise combat casualty care and reduce preventable death

- Multidisciplinary team of medical and non-medical subject matter experts establish guidelines aligned with the appropriate qualified personnel.

- These recommendations and processes for evaluating the trauma care system are clearly communicated to military leadership.

- Military leadership enforces the standardised implementation of these specified guidelines to train and equip the military trauma system.

- Military leadership enforces documentation and collection of relevant medical and non-medical data aligned with these guidelines necessary for a valid and reliable evaluation of the military trauma care system.

- Military leadership enforces rapid analysis and reporting of relevant metrics to evaluate the military trauma care system and inform actionable improvements.

- Military leadership prioritises, implements, adequately resources and enforces recommended improvements identified as part of this iterative evaluation of the military trauma care system to reduce preventable deaths across the entire Department of Defense. deaths, which is why adherence to, or lack thereof, must be considered in military preventable death reviews.

\section{Qualifications and training of prehospital personnel}

"Understanding individual skills, and the performance of those skills to support team, platoon, company and battalion level collective tasks, is crucial to ensuring the appropriate training focus required to support the desired effect of reduced preventable death."-SME 1 and 2

Prehospital SMEs concurred that all medical and non-medical military personnel should be proficient in prehospital trauma care commensurate to their role on the battlefield. To identify if lack of training and qualifications of personnel contributed to a fatal injury, a comprehensive understanding of the verified qualifications and skills of medical and non-medical personnel is essential.

\section{Medical data collection and evaluation}

Data elements captured from the prehospital setting include, but are not limited to, patient demographics, mechanism of injury, procedures and medications administered, and type (Medical Evacuation (MEDEVAC), Casualty Evacuation(CASEVAC)) and mode (air, ground, water) of transport to higher levels of care. While non-medical factors will often prevent capture of prehospital data in the prehospital setting, the collection of these elements is essential to understanding the medical context of a fatal injury.

\section{Non-medical recommendations}

Mission tactics, techniques and procedures

"You might have someone get injured early during a mission and despite all we say about never leaving someone on the battlefield 
Table 2 Environmental factors reported by subject matter experts

\begin{tabular}{|c|c|}
\hline Environmental factors & Definitions \\
\hline Altitude & High altitudes where oxygen will be limited. \\
\hline Austerity & $\begin{array}{l}\text { Having to perform a mission at or beyond the } \\
\text { limits of the system (eg, deep into the mountains, } \\
\text { desert, jungle or a submarine). }\end{array}$ \\
\hline Climate & $\begin{array}{l}\text { Desert, tropical, arctic climates in which constant } \\
\text { temperatures can affect equipment and supplies. }\end{array}$ \\
\hline Defensive equipment & $\begin{array}{l}\text { Protective equipment used to prevent and } \\
\text { mitigate injury. }\end{array}$ \\
\hline Enemy & Tactics, techniques and procedures. \\
\hline Illumination & Darkness or dimly lit settings. \\
\hline Insertion/Extraction by air & $\begin{array}{l}\text { Injuries from awkward landing, crashes, } \\
\text { parachuting; crush injury from heavy machinery. }\end{array}$ \\
\hline Insertion/Extraction by water & $\begin{array}{l}\text { Injuries from waves, falling off ship platform, } \\
\text { drownings. }\end{array}$ \\
\hline Offensive equipment & $\begin{array}{l}\text { Weaponry used to inflict injury and/or complete } \\
\text { the mission. }\end{array}$ \\
\hline Rural vs urban setting & $\begin{array}{l}\text { Differences in infrastructure and distance to } \\
\text { resources. }\end{array}$ \\
\hline Terrain & Difficult terrain (eg, the side of a mountain). \\
\hline Weather & $\begin{array}{l}\text { Inclement weather such as a blizzard, dust storm } \\
\text { or hurricane. }\end{array}$ \\
\hline
\end{tabular}

... that's not always true. If you're out there, the mission comes first." -SME 1

Mission-specific tactics, techniques and procedures (TTPs) may directly conflict with goals of patient care. Therefore, the TTPs implemented to complete the mission are important to consider during the preventable death review process, as they can turn a preventable death to a non-preventable one.

\section{Environmental factors}

"Austere is where you do not have the advantage of having modern technology in close proximity or relatively close proximity ... you are at or beyond the limits of your medical system." —SME 1 and 2

Environmental factors may include any combination of the factors reported by internal and external SMEs that impact mission and optimal care of casualties (Table 2).

\section{Multiple casualties occurring simultaneously}

The impact of multiple casualties on the provision of optimal care in the prehospital setting must be considered during preventable death determinations. Limited medical personnel are available in the tactical setting at any given time. Often, only one will be available; therefore, administering care can be challenging with simultaneous casualties and can negatively affect care.

\section{Non-medical data collection and evaluation}

Prehospital SMEs agreed that better non-medical data collection and evaluation are needed to properly conduct military preventable death reviews. These data provide vital information on the mission and TTPs, environmental factors, equipment, enemy, and timeline of the mission, which assist with classifying the death as preventable or non-preventable.

\section{In-hospital recommendations}

In-hospital care is defined as care provided in MTFs with the following capabilities: massive transfusions, damage control surgery, basic intensive care unit and the ability to sustain patients postoperatively with appropriate equipment and personnel. SME-recommended in-hospital medical and nonmedical considerations when conducting military preventable death reviews are listed below.

\section{Medical recommendations \\ Major surgical capabilities, definitive transfusion capabilities and postoperative care}

The most important differences between in-hospital care and prehospital care reported by all SMEs were the presence of resources to conduct major surgery and massive transfusion, damage control surgery, postoperative care, and the ability to stabilise and package patients for transfer to higher levels of care. While these resources are not unlimited in the in-hospital setting, they are more prevalent than in the prehospital setting, leading to provision of more sophisticated care. Therefore, when determining if a death was preventable, one must assess if personnel and resources were used appropriately to provide optimal care.

\section{Appropriately trained personnel and adequate resources}

In contrast to the prehospital setting, the in-hospital setting has more personnel and resources to provide optimal care. However, the ongoing concern remains that personnel may have inadequate training, experience or exposure to combat casualties, and lack resources to provide care in austere environments. Similarly, necessary equipment and supplies may be unavailable or unfamiliar to those personnel due to operational tempo, logistics or planning.

\section{Non-medical recommendations Logistics of supply and resupply}

"The items being supplied, where they are being delivered, and the difficulty of them being delivered are different in prehospital vs inhospital settings." - SME 3 and 4

MTFs in the in-hospital setting do not face the same obstacles and challenges as the prehospital setting, when it comes to supply and resupply of equipment, resources and personnel. Depending on proximity to and location within the combat zone, the logistics of getting equipment, resources and personnel to a site can prove quite challenging as it is often affected by enemy activity, availability and access to transport, fuel requirements, and conditions of terrain and weather. The ability to acquire these resources must be considered when evaluating care provided and determining whether a death was preventable.

\section{Transportation challenges}

"One primary issue is the availability and access to transport; as well as the level of medical and communication capabilities of that transport. For transport platforms with less capability than that of a Critical Care Air Transport Team (CCAT), we should not make assumptions about level of communication capability." —SME 4

Availability and access to transportation are an important factor when evacuating patients from the point of injury to the next level of care. Often, casualties in the prehospital setting are transported on non-medical platforms of convenience without the same medical capabilities often seen in the in-hospital setting, such as fixed-wing transport or ambulance. Transport availability can therefore significantly affect casualty transport time intervals between all roles of care, level of care provided and the preventability of a fatal injury. 
Communication and collaboration between non-medical and medical leadership

Providing care in the prehospital and in-hospital settings requires cooperation, communication and collaboration between medical and non-medical leadership. They must work together in a mutually supporting environment to achieve the mission and provide optimal care to casualties, and to share information on care provided across the continuum of care.

\section{Forensic pathology recommendations}

The Armed Forces Medical Examiner has authority to conduct forensic pathology investigations, including forensic autopsy, on any individual found dead or who dies on a garrisoned installation under exclusive jurisdiction, any US service member on active duty or inactive duty for training, recently retired US service members, and civilian dependents of US service members who are found dead or die outside of the USA. ${ }^{78}$ The following recommendations must be considered to contextually place the injuries depicted during the autopsy examination as part of a preventable death review process.

\section{Medical recommendations \\ Information on prehospital and in-hospital care}

Forensic pathology SMEs reported that prehospital and/or in-hospital care information is essential to the preventable death review process. Prehospital and in-hospital information necessary during this process includes TCCC cards, personal medical records, personal care records, surgical notes and description of medical intervention(s), time of death, mechanism of injury, injury type, procedure codes, and labs. Ideally, forensic pathologists would receive prehospital and in-hospital care information from all roles of care within 24 hours of the deceased arriving at the medical examiner's office.

\section{Non-medical recommendations}

\section{Command-directed and safety investigations}

All US military services conduct command-directed investigations when a service member is fatally injured. Forensic pathology SMEs state that access to command-directed investigations provides necessary background and context to injuries sustained and how they became fatal. These contextual factors surrounding a death are important to comprehensively understand during military preventable death reviews.

\section{Joint trauma analysis and prevention of injury in combat data}

Joint trauma analysis and prevention of injury in combat (JTAPIC) is a collaborative partnership consisting of US DoD medical, intelligence and materiel communities. JTAPIC can provide non-medical information necessary for a determination of preventability, such as personal protective equipment (PPE) worn by the individual during the event and operational context. Further, JTAPIC can provide information on potential vulnerabilities in operational tactics, vehicles and vehicular protective equipment that contributed to the fatal injury.

\section{DISCUSSION}

The purpose of this project was to have prehospital, in-hospital and forensic pathologist SMEs identify medical and nonmedical considerations to contemplate when conducting a well-informed, comprehensive military preventable death review (Box 2). Standardisation of the preventable death review process will promote optimal combat casualty care through enhanced identification of opportunities for improvement and ultimately

\section{Box 2 Summary of recommendations}

Prehospital recommendations.

Medical recommendations.

1. Prehospital medical standards: Tactical Combat Casualty Care.

2. Qualifications and training of prehospital personnel.

3. Medical data collection and evaluation.

Non-medical recommendations.

1. Mission tactics, techniques and procedures.

2. Environmental factors.

3. Multiple casualties occurring simultaneously.

4. Non-medical data collection and evaluation.

In-hospital recommendations.

Medical recommendations.

1. Major surgical capabilities, definitive transfusion capabilities and postoperative care.

2. Appropriately trained personnel and adequate resources.

Non-medical recommendations.

1. Logistics of supply and resupply.

2. Transportation challenges.

3. Communication and collaboration between non-medical and medical leadership.

Forensic pathology recommendations.

Medical recommendations.

1. Information on prehospital and in-hospital care.

Non-medical recommendations.

1. Command-directed and safety investigations.

2. Joint trauma analysis and prevention of injury in combat data.

reduce preventable deaths. A comprehensive understanding of the medical and non-medical factors provides a foundation to clearly and concisely recommend the data elements necessary to evaluate the military trauma care system. It is important to note that these recommendations have potential to change, and therefore should be part of an iterative, evolving evaluation process. Just as TCCC and JTS guidelines are regularly reviewed, revised and updated, ${ }^{9-14}$ according to the operational tempo, evidencebased research and improvements in medical care, these considerations will also need to be routinely edited and evaluated for feasibility, relevance and efficacy.

While many of the medical considerations have been reported in previous work, ${ }^{9-14}$ this qualitative study confirmed the importance of evaluating medical care in the context of non-medical factors. Additionally, the incorporation of SME opinions from AFMES was a novel approach that added key insights. Survivability of service members' injuries can remain solely a medical issue; however, an understanding of non-medical factors such as PPE and environmental factors is needed to truly understand, classify and mitigate preventable deaths. As expected, the many considerations needed to conduct a standardised preventable death review varied significantly across specialties; however, there were two common themes reported by all SMEs: (1) the need for improved data collection and evaluation, and (2) better communication and collaboration among prehospital, in-hospital and forensic pathologist leadership.

\section{Improved data collection and evaluation}

Data collection and evaluation are key factors in identifying where opportunities to provide optimal care were missed. The collection of these data is even more important in the prehospital combat setting, where $87 \%$ of deaths occur. ${ }^{13}$ While data 
collection can prove difficult in a combat zone, certain data must be reported for a well-informed preventable death review and to determine adherence to guidelines and provision of optimal care. Fundamentally, collection of these data elements needs to be mandated and enforced at all levels of the US DoD.

Increased communication and collaboration among providers Another important finding reported by SMEs was the need to improve lateral communication and upward communication through the chain of command to senior military leaders. Communication and collaboration among medical and nonmedical leadership at all levels will ensure that individuals conducting preventable death reviews will have complete casualty information along the entire continuum of care. ${ }^{15-17}$ Synergy between prehospital, in-hospital and forensic pathology leaders should begin well before a service member is injured.

\section{Limitations}

Limitations to this study include implementation of convenience sampling to identify internal and external SMEs, a low response rate among external SMEs, and a small sample size of internal (seven) and external (six) SMEs. Despite the small number of study participants, in qualitative research, quality of data sources is more important than quantity. The saturation point or repetition of themes for this project was obtained after conducting interviews with only seven (50\%) SMEs.

\section{CONCLUSIONS}

Prehospital, in-hospital and forensic pathology SMEs identified both medical and non-medical recommendations necessary for conducting a comprehensive preventable death review. The standardised, DoD-wide implementation of these recommendations when conducting preventable death reviews can lead to improved identification of opportunities for improvement in combat casualty care and reduced preventable death. Ultimately, for recommendations to penetrate the military trauma care system, they must be understood and implemented consistently throughout all military services. Otherwise, the military trauma system will be both disjointed, leading to variance in quality of care, and variable in methodology to measure, collect, analyse and report recommendations to improve the system.

Contributors All authors contributed significantly to the study design, data collection and management, analysis, drafting and finalisation of the manuscript.
Funding WYH was partially funded by the Southwest Center for Occupational and Environmental Health (SWCOEH), a National Institute for Occupational Safety and Health (NIOSH) Education and Research Center at The University of Texas Health Science Center at Houston School of Public Health, and awardee of grant no 5T42OH008421 from the (NIOSH)/Centers for Disease Control and Prevention.

Competing interests None declared.

Patient consent for publication Not required.

Ethics approval US Army Institute of Surgical Research Institutional Review Board.

Provenance and peer review Not commissioned; internally peer reviewed.

Data availability statement Data are available upon reasonable request.

\section{REFERENCES}

1 Janak JC, Sosnov J, Bares J, et al. Comparison of military and civilian potentially preventable death methodologies: a systematic review. JAMA Surgery 2018; 153:367-75

2 National Academies of Sciences, Engineering, and Medicine. A National trauma care system: integrating Military and civilian trauma systems to achieve zero preventable deaths after injury. Washington, DC: The National Academies Press, 2016.

3 Janak J, Stockinger Z, Mazuchowski E, et al. Military preventable death conceptual framework: a systematic approach for reducing battlefield mortality. Mil Med 2018;183(suppl_2):15-23.

4 Beebe J.Rapid assessment process. Encyclopedia of Social Measurement, 2004: 285-91.

5 Beebe J. Basic concepts and techniques of rapid appraisal. Hum Organ 1995;54:42-51.

6 Beebe J. Rapid assessment process: an introduction. Walnut Creek, CA: AltaMira Press, 2001.

7 DoD Instruction 5154.30. "Armed Forces Medical Examiner System (AFMES) Operations" 2015;7:591-603.

8 Mazuchowski EL, Gordon CJ, Finelli LN, et al. Beyond the forensic pathology investigation: improving Warfighter survivability. Acad Forensic Pathol 2017;7:591-603.

9 Butler FK, Hagmann J, Butler EG, et al. Tactical combat casualty care in special operations. Mil Med 1996;161 Suppl:3-16.

10 Butler FK. Two decades of saving lives on the battlefield: tactical combat casualty care turns 20. Mil Med 2017;182:e1563-8.

11 Butler FK. Tactical combat casualty care: update 2009. The Journal of Trauma: Injury, Infection, and Critical Care 2010;69(Supplement):S10-S13.

12 Butler FK, Holcomb JB, Giebner SD, et al. Tactical combat casualty care 2007: evolving concepts and battlefield experience. Mil Med 2007;172(11 Suppl):1-19.

13 Butler FK, Blackbourne LH. Battlefield trauma care then and now: a decade of tactical combat casualty care. J Trauma Acute Care Surg 2012;73(6 Suppl 5):S395-402.

14 Eastridge BJ, Mabry RL, Seguin P, et al. Death on the battlefield (2001-2011): implications for the future of combat casualty care. J Trauma Acute Care Surg 2012;73(6 Suppl 5):S431-7.

15 Montgomery HR, Butler FK, Kerr W, et al. TCCC guidelines comprehensive review and update: TCCC guidelines change 16-03. J Spec Oper Med 2017;17:21-38.

16 Butler FK. Leadership lessons learned in tactical combat casualty care. J Trauma Acute Care Surg 2017:82:S16-S25.

17 Kotwal RS, Montgomery HR, Miles EA, et al. Leadership and a casualty response system for eliminating preventable death. J Trauma Acute Care Surg 2017;82:S9-15. 